\title{
Rhizobium meliloti lacking mosA synthesizes the rhizopine scyllo-inosamine in place of 3-0-methyl-scyllo-inosamine
}

\author{
J. Papa Rao, Wojciech Grzemski and Peter J. Murphy
}

Department of Crop Protection, Waite Agricultural Research Institute, University of Adelaide, Glen Osmond, South Australia 5064, Australia
Author for correspondence: Peter J. Murphy. Tel: +618 303 7262. Fax: +618 3794095. e-mail:pmurphy@waite.adelaide.edu.au

Keywords: rhizopine synthesis genes, Rbizobium meliloti, symbiosis

\section{INTRODUCTION}

Rhizopines are synthesized in bacteroids within nodules during the symbiotic interaction between legumes and certain rhizobia. To date two rhizopines have been found, 3-O-methyl-scyllo-inosamine (3-O-MSI) and scyllo-inosamine (SI) (Murphy et al., 1987, 1988, 1993, 1994; Murphy \& Saint, 1992; Saint et al., 1993). In a recent survey about $10 \%$ of Rhizobium meliloti and Rbizobium leguminosarum bv. viciae but not $R$. leguminosarum bv. trifolii were found to produce one or the other of these rhizopines (Wexler et al., 1995). The genes for rhizopine biosynthesis (mos genes) have been investigated in two strains of $R$. meliloti, L5-30 and Rm220-3 which produce 3-O-MSI and $S I$, respectively. The mos genes from both of these strains are located on the nod-nif symbiotic plasmid and are regulated by NifA/NtrA type symbiotic promoters (Murphy et al., 1987; Murphy \& Saint, 1992; Saint et al., 1993).

Where detailed studies have been conducted the rhizopine

Abbreviations: HVPE, high-voltage paper electrophoresis; 3-O-MSI, 3-Omethyl-scyllo-inosamine; SI, scyllo-inosamine.

The GenBank accession number for the mos sequence reported in this paper is U23753. catabolism genes (moc) have been shown to be closely linked to the synthesis genes (Murphy et al., 1987; Murphy \& Saint, 1992; Saint et al., 1993). Thus thizopines, which are synthesized in nodules only by certain biovars, are catabolized by free-living bacteria and may result in a selective advantage for those bacteria. These strains have a competitive advantage in nodulation (Murphy \& Saint, 1992; Murphy et al., 1995).

The L5-30 mos operon consists of four ORFs termed $\mathrm{ORF} 1, \operatorname{mos} A, B$ and $C$. Although ORF1 is transcribed as part of the mos operon no translation product can be found in nodules, nor is a functional protein from this ORF required for rhizopine biosynthesis (Murphy et al., 1993). The sequence of a 320 nucleotide region covering the promoter and part of ORF1 of the SI-producing strain Rm220-3 has been reported (Saint et al., 1993). Furthermore, regions equivalent to $\operatorname{mos} B$ and $C$ but not $\operatorname{mos} A$ of L5-30 were detected by Southern hybridization in the Rm220-3 mos locus.

In this study, to provide further insight into the structure of mos genes, the complete sequence of the $\mathrm{Rm} 220-3$ mos locus is reported. The precise nature of the nucleotide sequence surrounding deletion breakpoints of a region equivalent to L5-30 mos $A$ is defined in the $\mathrm{Rm} 220-3$ mos operon. Antibodies were also used to detect Mos proteins 
in nodules. We also provide direct evidence for the involvement of the L5-30 MosA protein in the conversion of $S I$ to $3-O-M S I$ in symbiotic nodules.

\section{METHODS}

Bacterial strains, plasmids and growth conditions. R. meliloti and Escherichia coli strains, plasmids constructed and used in this study are listed in Table 1. E. coli was grown in Luria-Bertani (LB) medium (Miller, 1972) at $37^{\circ} \mathrm{C}$. Antibiotic concentrations used in the LB medium for $E$. coli cultures with plasmids were $100 \mu \mathrm{g}$ ampicillin $\mathrm{ml}^{-1}, 12 \mu \mathrm{g}$ tetracycline $\mathrm{ml}^{-1}$ and $30 \mu \mathrm{g}$ kanamycin $\mathrm{ml}^{-1}$. R. meliloti $\mathrm{Rm} 1021$ was grown in TY complex medium (Beringer, 1974) at $28^{\circ} \mathrm{C}$. Bacterial triparental matings (Murphy et al., 1987) were performed at $28^{\circ} \mathrm{C}$ on TY medium. R. meliloti strains containing plasmids with cloned L5-30 mos genes were selected and maintained on TY medium containing $100 \mu \mathrm{g}$ rifampicin $\mathrm{ml}^{-1}$ and $12 \mu \mathrm{g}$ tetracycline $\mathrm{ml}^{-1}$.

Plasmid DNA extraction and manipulations. Plasmid DNA extraction, manipulation and analysis was carried out by standard procedures (Sambrook et al., 1989). For generating nested deletions with exonuclease III (Henikoff, 1984), closed circular DNA was purified by acid phenol extraction as described (Zasloff et al., 1978). This procedure was also used to selectively remove traces of linear background DNA from plasmid DNA that was used for sequencing reactions. DNA ligation and restriction enzyme digestion of plasmid DNA were according to the manufacturer's instructions (Boehringer Mannheim). E. coli JM109 competent cells for plasmid DNA transformation were prepared as described (Alexander, 1987). DNA fragments from agarose gels were isolated and purified using the GenecleanII kit (Bio 101)

Table 1. Bacterial strains and plasmids

\begin{tabular}{|c|c|c|}
\hline Strain or plasmid & Relevant characteristics & Reference/source \\
\hline \multicolumn{3}{|l|}{ Strain } \\
\hline \multicolumn{3}{|l|}{ E. coli } \\
\hline JM109 & & Promega \\
\hline BL21(DE3) & & Novagene \\
\hline \multicolumn{3}{|l|}{ R. meliloti } \\
\hline $\mathrm{Rm} 220-3$ & $\operatorname{Mos}^{+} \mathrm{Moc}^{+} \operatorname{Str}^{\mathrm{r}}$, produces $S \mathrm{I}$ & Gift from A. Pühler, Saint et al. (1993) \\
\hline L5-30 & $\mathrm{Mos}^{+} \mathrm{Moc}^{+}$, produces 3-O-MSI & Dénarié, J. Kowalski (1967) \\
\hline $\operatorname{Rm} 1021$ & $\mathrm{Mos}^{-} \mathrm{Moc}^{-}$ & Meade et al. (1982) \\
\hline $\mathrm{Rm} 1021 \mathrm{Rif}^{\mathrm{r}}$ & $\operatorname{Mos}^{-} \operatorname{Moc}^{-} \operatorname{Rif}^{r}$ & This study \\
\hline \multicolumn{3}{|l|}{ Plasmid } \\
\hline pPM1169 & $\begin{array}{l}\mathrm{Mos}^{+} \mathrm{Moc}^{-}, 3 \cdot 5-, 1 \cdot 0-\text { and } 7 \cdot 3 \mathrm{~kb} H \text { indIII } \mathrm{Rm} 220-3 \\
\text { fragments of pPM1153 in pVK102, } \mathrm{Km}^{\mathrm{s}}, \mathrm{Tc}^{\mathrm{r}}\end{array}$ & Saint et al. (1993) \\
\hline pPM1062 & $\begin{array}{l}\mathrm{Mos}^{+} \mathrm{Moc}^{-}, 3 \cdot 4-\text { and } 6.9 \mathrm{~kb} \text { EcoRI fragments of L.5-30 in } \\
\text { pLAFR1, Tc }\end{array}$ & Murphy et al. (1987) \\
\hline pPM1242 & $\begin{array}{l}5.7 \mathrm{~kb} N d \mathrm{I}-A p a \mathrm{I} \mathrm{L} 5-30 \text { mos fragment from pPM1062 } \\
\text { cloned into pGEM-7Zf( }+ \text { ) }\end{array}$ & This study \\
\hline pPM1242a & $\begin{array}{l}2.45 \mathrm{~kb} \text { ApaI-SacI L5-30 mos fragment of pPM1242 } \\
\text { cloned into pGEM-7Zf }(+)\end{array}$ & This study \\
\hline pPM1242b & $\begin{array}{l}\text { Clone derived from pPM1242a after an in-frame deletion } \\
\text { of L5-30 mos } A \text { ORF }\end{array}$ & This study \\
\hline pJPM1 & $\begin{array}{l}\text { 3.65 kb } K p n \mathrm{I}-A p a \mathrm{I} \mathrm{Rm} 220-3 \text { mos fragment cloned into } \\
\text { pGEM-7Zf (+) }\end{array}$ & This study \\
\hline pJPM2 & $\begin{array}{l}\text { Obtained from pJPM1 with deletion of } 1.13 \mathrm{~kb} \text { EcoRI } \\
\text { fragment }\end{array}$ & This study \\
\hline pJPM3 & $\begin{array}{l}1.13 \mathrm{~kb} \text { EcoRI fragment of PJPM1 cloned into pGEM- } \\
7 \mathrm{Zf}(+)\end{array}$ & This study \\
\hline pJPM4 & $\begin{array}{l}\text { L5-30 mos } A \text { ORF in-frame deletion mutant derived from } \\
\text { pPM1242 }\end{array}$ & This study \\
\hline pJPM5 & $\begin{array}{l}5 \cdot 7 \text { kb L5-30 mos DNA from pPM1242 cloned into } \\
\text { pLAFR3 }\end{array}$ & This study \\
\hline pJPM6 & $\begin{array}{l}4.85 \text { kb L5-30 mos DNA from pJPM4 cloned into } \\
\text { pLAFR } 3\end{array}$ & This study \\
\hline pGEM-7Zf $(+)$ & Cloning and sequencing vector & Promega \\
\hline PLAFR3 & pLAFRI, $T c^{\mathrm{r}}$ cosmid cloning vector, containing $X b a \mathrm{I}$ site & Friedman et al. (1982) \\
\hline pRK2013 & $\mathrm{Km}^{\mathrm{r}}$ helper plasmid & Figurski \& Helinski (1979) \\
\hline pVK102 & $\mathrm{Tc}^{\mathrm{r}} \mathrm{Km}^{\mathrm{r}}$ cosmid cloning vector & Knauf \& Nester (1982) \\
\hline pGEMEX-1 & Expression cloning vector & Promega \\
\hline pLysS & & Novagene \\
\hline pLysE & & Novagene \\
\hline
\end{tabular}






Fig. 1. Partial restriction map of the $R$. meliloti Rm220-3 mos locus and cloning and sequencing strategy for both strands. $\square$, Previously sequenced $5^{\prime}$ region; 四, pGEM-7Zf $(+)$ sequence; $B$, Apal-Kpnl blunt-end ligation site. The clones containing $3.65 \mathrm{~kb}$ Kpnl-Apal, $2.52 \mathrm{~kb}$ EcoRl-Apal and $1.13 \mathrm{~kb}$ Kpnl-EcoRI Rm220-3 mos fragments in pGEM-7Zf $(+)$ are designated pJPM1, pJPM2 and PJPM3, respectively. Arrows show the direction of sequencing with nested deletions. Restriction sites are not drawn to scale on the vector sequence.

Cloning and sequencing of DNA. A $3.65 \mathrm{~kb} K p n \mathrm{I}-A p a \mathrm{I}$ DNA fragment containing most of the $\mathrm{Rm} 220-3$ mos locus was isolated from pPM1169, a pVK102 based cosmid clone containing this locus. This fragment was cloned into the $K p n I$ site of pGEM-7Zf $(+)$ using a strategy (Fig. 1) designed to enable the nucleotide sequencing of both strands. The $3.65 \mathrm{~kb} \mathrm{KpnI-}$ $A p a \mathrm{I}$ fragment was first ligated with $K p n \mathrm{I}$-digested pGEM$7 \mathrm{Zf}(+) \mathrm{DNA}$, then the $K p n \mathrm{I}$ and $A p a \mathrm{I}$ cohesive ends were blunt-ended by the fill-in reaction using Klenow DNA polymerase (Promega), then ligated and the plasmid construct was introduced into E. coli JM109 by transformation. The resulting recombinant clones were found to have the DNA inserted in only one direction (PJPM1) as shown in Fig. 1. To provide a unique restriction site that protects DNA from exonuclease III activity, to facilitate the generation of unidirectional nested deletions for the second strand sequencing, the recombinant plasmid PJPM1 was cut with EcoRI and a $5.52 \mathrm{~kb}$ EcoRI-EcoRI fragment that contained a $2.52 \mathrm{~kb}$ mos EcoRI-ApaI region was isolated and re-ligated (pJPM2). The other $1.13 \mathrm{~kb}$ EcoRIEcoRI fragment, containing a KpnI-EcoRI DNA segment of mos region, was cloned into the EcoRI site of pGEM-7Zf $(+)$ and a clone having the insert in the required direction was selected (pJPM3).

Unidirectional deletions were generated in both orientations of the mos DNA by exonuclease III and S1 nuclease digestion (Henikoff, 1984), using the 'Erase-a-Base' kit (Promega). For pJPM1 and pJPM3 clones, the ApaI site was used to protect against exonuclease III activity and the $X b a I$ site was used for unidirectional deletion. For the pJPM2 clone, the $S_{a c}$ I site was used to block the exonuclease III activity and the $S \mathrm{maI}$ site was used for exonuclease III activity. PJPM1 and pJPM3 clones and their nested deletions were sequenced using the M13 forward sequencing primer, and PJPM2 and its nested deletion clones were sequenced with the M13 reverse primer. Sequences were determined by the dideoxy method (Sanger et al., 1977), of double-stranded DNA templates using a Prism ready reaction dye primer cycle sequencing kit (Applied Biosystems) and were analysed with an Applied Biosystems DNA sequencer (model 373 A).

DNA sequence analysis. Nucleotide sequences were examined and aligned using the SeqEd 1.0 computer program (Applied Biosystems). Further analysis was done by the University of
Wisconsin GCG program version 7.0 (Devereux et al., 1984), and also by the DNA Strider PC program.

Preparation of antibodies and Western blotting. Antibodies were prepared from over-expressed fusion proteins of ORF1, Mos A, -B and -C from R. meliloti L5-30 as described by Murphy et al. (1993). Rm220-3 nodule protein extracts were separated by SDS-PAGE and the gels were blotted onto nitrocellulose membranes and probed with antibodies prepared to L5-30 Mos proteins as described by Murphy et al. (1993)

Construction of a L5-30 mosA deletion mutant. An L5-30 mos $5.7 \mathrm{~kb}$ NdeI-ApaI DNA fragment obtained from pPM1062, a pLAFR1 clone containing this locus, was blunt-ended with T4 DNA polymerase (Boehringer Mannheim), then XbaI-linkered and cloned into the pGEM-7Zf $(+)$; this plasmid was termed pPM1242. An internal in-frame deletion of $\operatorname{mos} A$ was prepared utilizing two BamHI sites separated by $771 \mathrm{bp}$ (Fig. 5). To avoid the $\mathrm{BamHI}$ site in the polycloning region of the pGEM-7Zf $(+)$ sequence, pPM1242 was cut with SacI, and the $3.25 \mathrm{~kb}$ SacI-SacI fragment containing the vector Bam HI site was eliminated. The remaining $5.45 \mathrm{~kb}$ SacI-SacI fragment containing the vector and mos sequence was ligated (creating pPM1242a), and the plasmid construct was introduced into $E$. coli JM109 by transformation. The plasmid DNA from this clone was digested with BamHI, blunt-ended with 1 unit mung bean nuclease per $\mu \mathrm{g}$ DNA (New England Biolabs), and incubated at $30^{\circ} \mathrm{C}$ for $30 \mathrm{~min}$, then ligated and the plasmid construct was introduced into $E$. coli JM109 by transformation. To check that the remaining $\operatorname{mos} A$ region maintained the original reading frame, the region bordering the deletion was sequenced. For this purpose an ApaI-StuI fragment was removed from the Bam HI-Bam HI deletion clone (pPM1242b), blunt-ended with mung bean nuclease, ligated and sequenced using the forward sequencing primer as described above. To complete the construction of the mos $A$ deletion mutant, a $1.6 \mathrm{~kb} A p a \mathrm{I}-S a c \mathrm{I}$ fragment from pPM1242b was cloned into a $6.25 \mathrm{~kb} A p a \mathrm{I}-S a c \mathrm{I}$ fragment (from pPM1242) that contained the pGEM-7Zf $(+)$ sequence and a $3.2 \mathrm{~kb}$ fragment of the mos region. The resulting deletion construct of the mos operon, pJPM4, is a $4.85 \mathrm{~kb} \mathrm{XbaI-XbaI} \mathrm{mos}$ fragment cloned into the $X b a \mathrm{I}$ site of $\mathrm{pGEM}-7 \mathrm{Zf}(+)$.

The $4.85 \mathrm{~kb} X b a \mathrm{I}-X b a \mathrm{I}$ L5-30 mos fragment from pJPM4 was further cloned into the $X b a I$ site of pLAFR3, a broad host range vector to enable mobilization into $R$. meliloti, and this clone was termed pJPM6. The $5.7 \mathrm{~kb} X b a I-X b a I$ L5-30 mos fragment from $\mathrm{pPM} 1242$ was cloned into the $X b a \mathrm{I}$ site of PLAFR3 vector, resulting in PJPM5, which served as the wild-type control clone for the deletion mutant of PJPM6.

Detection of rhizopines from nodules. Plasmids pJPM5 and pJPM6 were mobilized from E. coli to R. meliloti $\mathrm{Rm} 1021 \mathrm{R}^{\mathrm{T}}$ by triparental mating (Murphy et al., 1987), with the helper plasmid pRK2013 on TY medium at $28^{\circ} \mathrm{C}$. Alfalfa plants, grown on agar medium (Kondorosi et al., 1977) in glass tubes, were inoculated separately with Rm1021 carrying either pJPM5 (a $\operatorname{mos} A$ control plasmid) or pJPM6 (a mos $A$ mutant construct). Wild-type $R$. meliloti L5-30 and Rm220-3 strains producing 3$O$-MSI or SI, respectively, and strain $\mathrm{Rm} 1021$ (which does not produce any rhizopines), were also inoculated onto alfalfa plants to serve as controls. Nodules were harvested after 6 weeks. Nodule extracts were prepared in water and checked for rhizopine biosynthesis by high-voltage paper electrophoresis (HVPE) using formic acid/acetic acid buffer, $\mathrm{pH} 1.7[28.4 \mathrm{ml}$ $98 \%(\mathrm{v} / \mathrm{v})$ formic acid and $59 \cdot 2 \mathrm{ml}$ glacial acetic acid per l], and staining with $\mathrm{AgNO}_{3}$ as previously described (Murphy et al., 1987; Saint et al., 1993). 


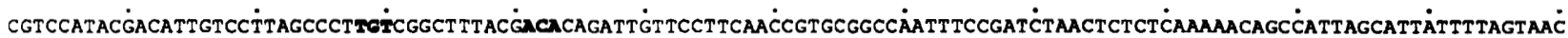
TCCCTCGGCCTEGCACGACTT TrGCACGATCAGCCCTGGGCGCGCATGCTGTTGCGCATTCATGTGTCGGAACAACCGAAATAGTTTAAACAACAAAGGAAGCAGATGGCAGCTCGGCG TCAGATCGCGTTCTACGGCAAGGGGGGTACCGGCAAGCCCAAGCGAAAGCCTGAGCCGGTAACCGCATCCAAGGAAGATAGATGCCTCGGCTRCCCG ODT1 Kpn I

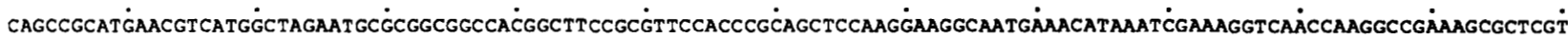

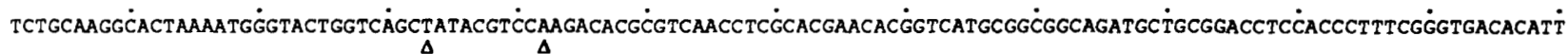

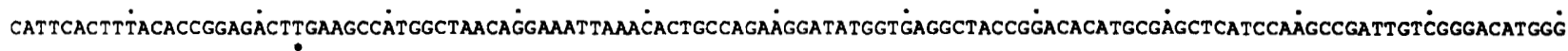



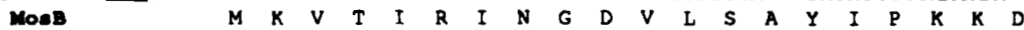

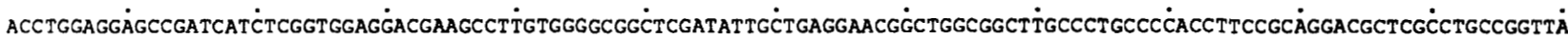
$\begin{array}{llllllllllllllllllllllllllllllllllllllllll}L & E & E & P & I & I & S & V & E & D & E & A & L & W & G & G & S & I & L & L & R & N & G & W & R & L & A & L & P & H & L & P & Q & D & A & R & L & P & V & T\end{array}$

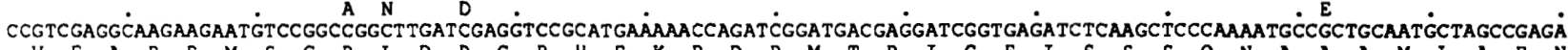



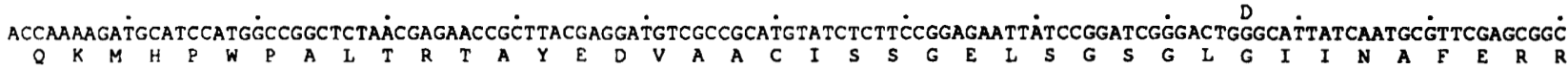
GCATGGAGGAATGGATCGGCGGGGGTTATǴTGGTCTCGGCAAGTAGCGGCACAGCCGCCC̈TGACAGTGGCGGTCATAGCTCTCGGCATCCAGCCGGGGGACGTTGTGCTTCTGCCTTCCT

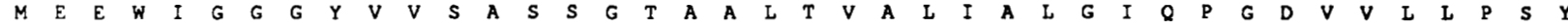





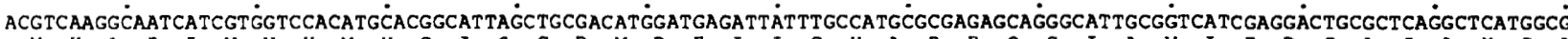

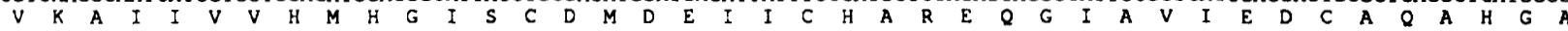

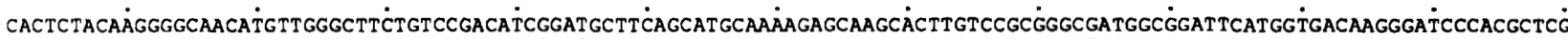

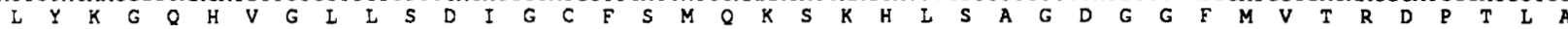

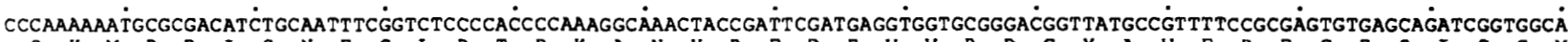

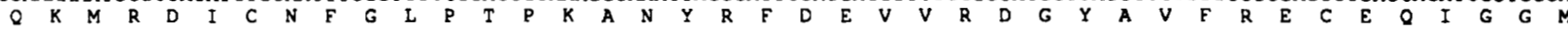
TGT TCAGGTTACAGCCGATĠTCCGCGGCTCTGGTGATGCACCAGCTAGAGCATCTGCGCCAGCGGATCGCCTGGCTTCAÄACTGCAATGGaACCTCTGGTCGAGGAGTCTGCTAAAATCC

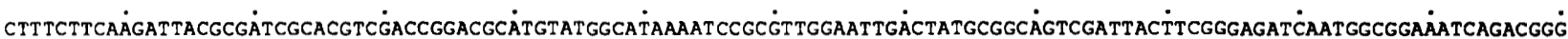

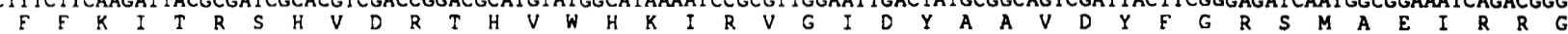



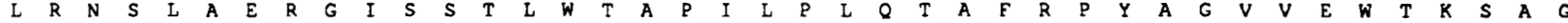

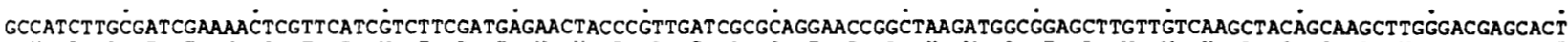

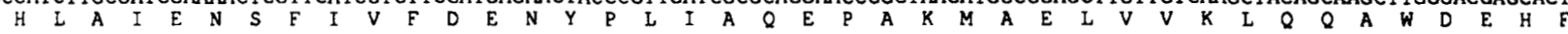

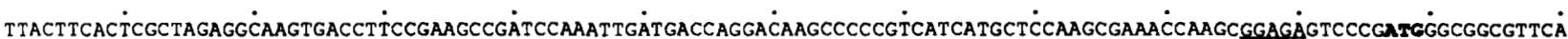

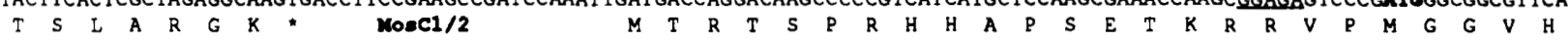

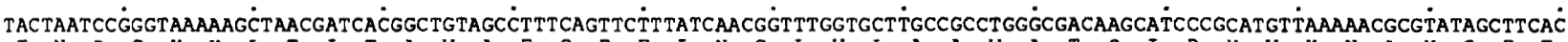


CGACGCCGAACTCGGCGTCG̈GGCTCCTAATCATGGCGGCGGGGGCGTTGCंTATTCATGTCGGCTAGCGGGTTATTTTCCGCACGTTTTCGGCAGCCGCCGCATGTCGAATCAATCCGCCCT

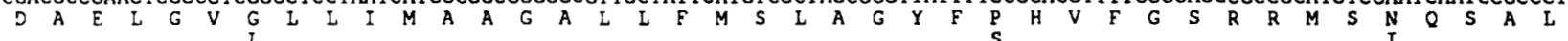

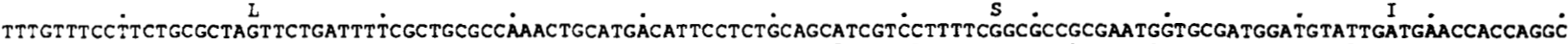




$K$
$K$

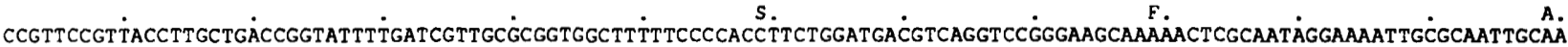

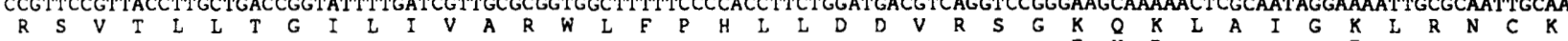
GCTCCTTATGTTCGGAATCTTGTCGTTCCTGACAATGGTGACCGACGGTGCAATTGCTGAATGGAGCAAGCTCTATCTCAंTTCGCGTTGGACAGGTGACA GATCAAGTGGGCTCTTTAGG

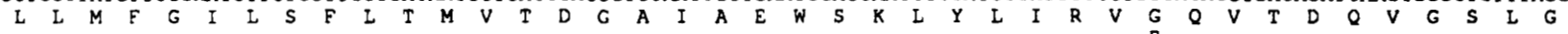

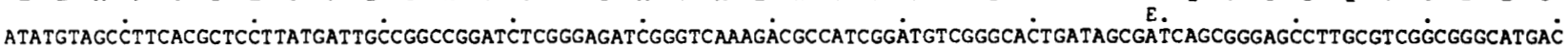
$Y$
$V$

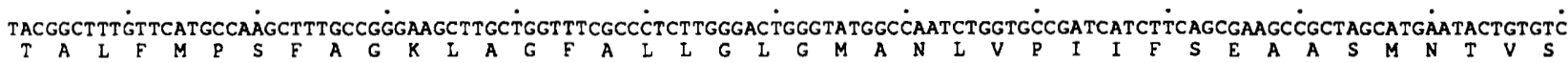

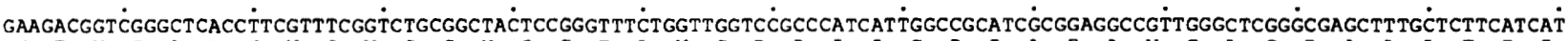
\begin{tabular}{lllllllllllllllllllllllllllllllllllllllll}
$K$ & T & $V$ & $G$ & L & $T$ & $F$ & $V$ & $S$ & $V$ & $C$ & $G$ & $Y$ & $S$ & $G$ & $F$ & L & V & $G$ & P & P & I & I & $G$ & R & I & A & E & A & V & $G$ & L & $G$ & $R$ & A & L & L & $F$ & $I$ & $I$ \\
\hline
\end{tabular} EGCGGTCGGÁGTGATCGTAGCTTGTGCTTC̈GGTATTCTTCGGACCGTCACAGATCAGGCCAGCCAGAGCCTTGATTATCCCATGCGCGAACCCTTGGGGGCCACTTCATGGCCGCTTGCAT A V G V I V A C A S V F F D R H R S G Q P E P *


AAAACGACCAGACGCGATGGCGTTCGCAAAGTCCTCAAACAAGGCCAGGAGGAGAACCTGAAGGCGGTTTTTGATCGTCTGATTCCTGGAGATTAGTTGGGGCCATCGGCATCGGGAGCG AAAACGACCAGACGCGATGGCGT TCGCAAAGTCCTCAAACAAGGCCAGGAGAGAACCTGAAGGCGGTTTTTGATCGTCTGATTCC GGCTGTCTTGACTTCCTCGACGACCAACTGGCGGGAGGATATGGCGAGGGTTCGACGATCTATCGAGATG 3910

Fig. 2. Nucleotide and deduced amino acid sequences of $\mathrm{Rm} 220-3$ mos operon. The sequence is determined for both strands. The NifANNtrA-binding sites within the mos promoter are bold-faced. The amino acid sequences are shown for mos $B$ and mosC. Where the Rm220-3 amino acid sequence differs from that of L5-30 the L5-30 sequence is indicated underneath that of Rm220-3. The potential Shine-Dalgarno sequence for each gene is indicated by single underlining before the ATG start codon. The likely rho-independent terminator is indicated $(>>>>)$. The sequence of the region

120 240 360 480 600 720 840 960 1080 1200 


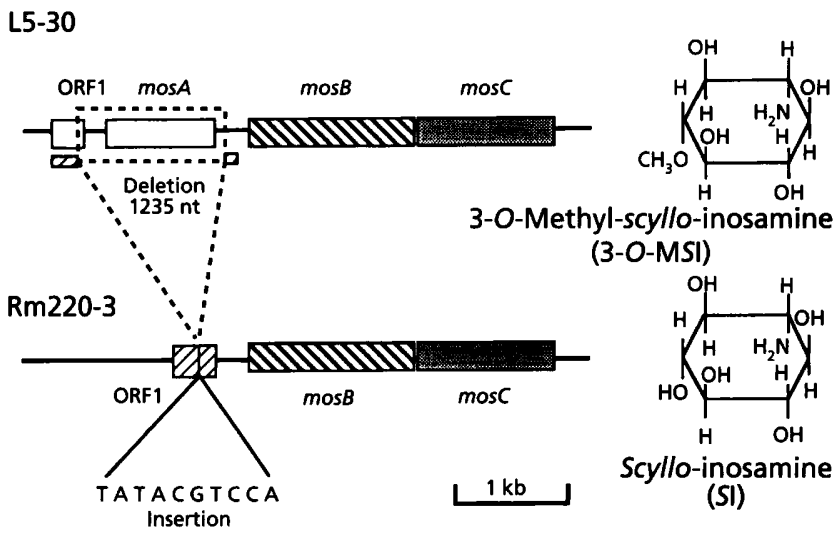

Fig. 3. Schematic representation of ORFs from $R$. meliloti L5-30 and $\operatorname{Rm} 220-3$ mos operons. The natural deletion of the L5-30 mosA region present in $\mathrm{Rm} 220-3$ is boxed with broken lines. The corresponding regions of the L5-30 mos operon which form the Rm220-3 mos ORF1 are boxed ( $\square$ ). The site of a novel 10 bp insertion in the Rm220-3 ORF1 is shown. Structures of 3-O-MSI and $\mathrm{SI}$ are shown towards the right of L5-30 and Rm220-3 ORFs, respectively.

\section{RESULTS AND DISCUSSION}

\section{Structure of the Rm220-3 mos locus}

We have analysed the rhizopine SI synthesis genes (mos) from $R$. meliloti strain Rm220-3 and defined three ORFs that are organized in a $3.9 \mathrm{~kb}$ operon unit (Fig. 2). By analogy with the L5-30 mos locus which produces the rhizopine 3-O-MSI these ORFs have been termed ORF1 (396 bp), mosB (1521 bp) and mosC (1221 bp). The Rm220-3 mos locus has a large deletion encompassing a region equivalent to the entire mos $A$ gene of L5-30 with the remainder of the locus, including the $5^{\prime}$ and $3^{\prime}$ untranslated regions being similar to the L5-30 mos locus. Excluding the deleted region there is $98.26 \%$ sequence conservation between Rm220-3 and L5-30 mos operons.

The $1235 \mathrm{bp}$ deletion (1276-2510 nt, of the L5-30 mos sequence, GenBank accession number L17071) in the $\mathrm{Rm} 220-3$ mos locus spans a region equivalent to the entire L5-30 $\operatorname{mos} A$ gene as well as $203 \mathrm{nt}$ upstream and $33 \mathrm{nt}$ downstream (Figs 2,3). The deleted region upstream of $\operatorname{mos} A$ consists of $14 \mathrm{nt}$ of the $3^{\prime}$ end of the L5-30 mos ORF1 (including the stop codon) and $189 \mathrm{nt}$ of the intercistronic region between ORF1 and $\operatorname{mos} A$. Consequently, the structure of Rm220-3 ORF1 differs from that of L5-30. Both have very similar $5^{\prime}$ regions but differ in their 3' region, with Rm220-3 ORF1 being 96 nt longer, incorporating part of the DNA sequence which is in the L5-30 $\operatorname{mos} A$ and $B$ intercistronic region. In the $286 \mathrm{bp}$ region common to L5-30 and Rm220-3 ORF1 (227512 nt, Fig. 2), there are 12 single base changes and two deletions of 3 bases which are $14 \mathrm{bp}$ apart. The majority of these changes occur just prior to the point where these sequences diverge. At the point of divergence in $\mathrm{Rm} 220-3$ (where the deletion starts) a $10 \mathrm{bp}$ sequence (TATACGTCCA) not found in the L5-30 mos $A$ region (Fig. 3) is present. Although this is suggestive of a footprint left by a departing transposon, the region in L5-30 corresponding to the deletion contains no repeated sequences characteristic of transposons (Döring \& Starlinger, 1986).

$\mathrm{Rm} 220-3$ and L5-30 mos $B$ and $\operatorname{mos} C$ are the same size and have extensive sequence identity. There are 18 single nucleotide changes in mos $B$ and 17 single nt changes, one $\mathrm{nt}$ addition and one nt deletion in mosC of the $\mathrm{Rm} 220-3$ mos operon as compared with the corresponding regions in the L5-30 mos operon. There are no differences in potential Shine-Dalgarno sequences and initiation codons for ORF1, mos $B$ and $\operatorname{mos} C$ in these operons. The sequence homology also extends to the untranslated $3^{\prime}$ region with only $7 \mathrm{bp}$ differences in a $357 \mathrm{bp}$ region.

As with the L5-30 mos locus two in-frame translational initiation codons are present for mos $C$, ORFs $C 1$ and $C 2$. The molecular masses of polypeptides expected to be encoded by mos ORFs are 14.6 (ORF1), 56 (MosB), 43.1 (MosC1) and $40.9 \mathrm{kDa}$ (MosC2), respectively. Putative Shine-Dalgarno sequences are present upstream of ORF1, mos $B$ and mos $C 2$ initiation codons. mos $C 1$ translation may result from a read-through of ribosomes following on from the mos $B$ termination codon.

A comparison of the amino acids coded by L5-30 and $\mathrm{Rm} 220-3$ mos $B$ and $\operatorname{mos} C$ genes reveals that there are five amino acid changes for MosB proteins and 26 amino acid changes for MosC proteins (Fig. 2). Most of the changes in $\mathrm{Mos} C$ are in the carboxy-terminal end of the protein and are the result of a frame-shift. In this region, the $\mathrm{Rm} 220-3$ MosC region reverts to the same frame as L5-30 MosC, 17 amino acids downstream of the point of divergence.

\section{Does Rm220-3 mos ORF1 produce a polypeptide in vivo?}

Recently we reported that L5-30 MosA, B and C are translated in vivo, whereas the translation product of ORF1 was not detected (Murphy et al., 1993). Rm220-3 ORF1 has a similar $5^{\prime}$ region ( $286 \mathrm{bp}$ ) to that of L5-30 but has an extended $3^{\prime}$ region. Therefore, it was of interest to see if these changes resulted in a translation product being detectable in nodules. To detect the presence of $\mathrm{Rm} 220-3$ Mos polypeptides in nodules, nodule extracts were analysed by Western blotting using purified antibodies prepared against over-expressed L5-30 Mos fusion polypeptides. The results of Western blots of Rm220-3 nodule extracts (Fig. 4) reveal that $56 \mathrm{kDa}$ MosB (lane 5),

upstream of the Kpnl site has been reported previously (Saint et al., 1993). Stop codons of the ORFs are asterisked. The ATG for ORF1 is double underlined. The in-frame ATG start site for mosC2 initiation is bold-faced. The site of a 10 bp sequence insertion, that replaced the deletion of L5-30 mosA region, in Rm220-3 mos ORF1 is indicated $(\triangle, \triangle)$ 




Fig. 4. Western blot of Rm220-3 mos polypeptides. Protein extracts from nodules induced by $R$. meliloti $R$ m220-3 were probed with antibodies raised to L5-30 mos proteins. Lane 1, marker proteins (Bio-Rad low range) stained with Coomassie blue; lanes 2-7, total protein, from $R$. meliloti $\mathrm{Rm} 220-3$ induced nodules, stained with Coomassie blue (lane 2) or blotted and probed with antibodies to: the C-terminal region of the deduced protein from L5-30 mos ORF1 (lane 3), mosA (lane 4), mosB (lane 5), the hydrophilic N-terminal region of mosC (lane 6) (detects MosC1), and the hydrophobic region of mosC (lane 7) (detects MosC1 and MosC2). For details of antibody preparation see Murphy et al. (1993).

$43 \cdot 1 \mathrm{kDa}$ MosC1 (lanes 6 and 7 ) and $40 \cdot 9 \mathrm{kDa}$ MosC2 (lane 7) proteins are detected. As expected, due to the absence of mos $A$ in the $\mathrm{Rm} 220-3$ mos locus the MosA antibody, which detects MosA in L5-30 (Murphy et al., 1993), did not detect a protein (Fig. 4; lane 4). This result also indicates that there is no other $\operatorname{mos} A$ gene elsewhere in the genome of $\mathrm{Rm} 220-3$. Similarly, as with L5-30 no ORF1 protein (predicted to be $14.6 \mathrm{kDa}$ ) was detected in Rm220-3 (Fig. 4; lane 3). Since the antibody raised against ORF1 of L5-30 was prepared from a region common to L5-30 and Rm220-3, it would be expected to detect a protein if one were present. At present we cannot distinguish between the possibilities that this protein is absent because it is not synthesized or because it is rapidly degraded. Nevertheless, the conservation of the $5^{\prime}$-regions of ORF1 from Rm220-3 and L5-30, as well as with the nfeI locus (which is involved in nodulation competitiveness in R. meliloti GR4, Soto et al., 1993), suggests that this region has an important role; such as in mRNA stability.

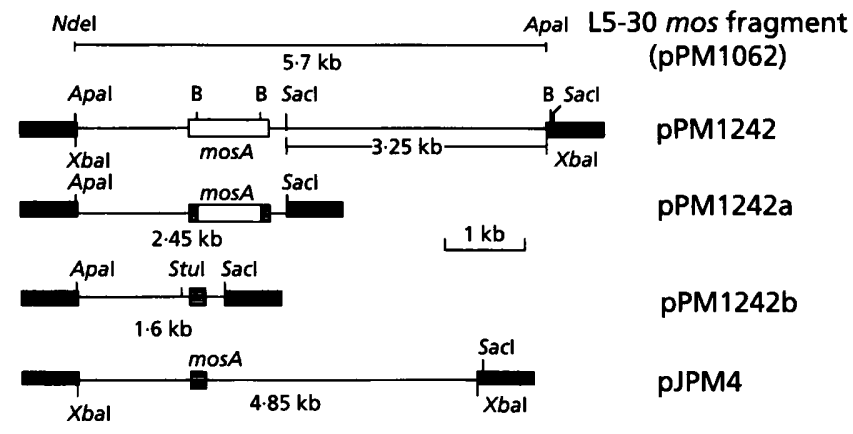

Fig. 5. Strategy for construction of the deletion within the mosA ORF of the L5-30 mos operon. PGEM-7Zf(+) DNA is indicated ( $\square$ ). An L5-30 $5.7 \mathrm{~kb}$ Ndel-Apal mos DNA fragment was Xbal-linkered and cloned into pGEM-7Zf( + ), (pPM1242). A $2.45 \mathrm{~kb}$ Apal-Sacl mos fragment in pGEM-7Zf( + ) (pPM1242a) was used for preparing the mosA deletion within the mosA ORF which was then sequenced to verify the original reading frame maintained (see Methods). The $4.85 \mathrm{~kb}$ Xbal-Xbal mosA deletion construct in pGEM-7Zf(+) is pJPM4. The deleted sequence is represented $(\square)$ and the truncated mos $A$ is shown (睼). B indicates BamHI site. Restriction sites are not drawn to scale on the vector sequence.

\section{Evidence for involvement of L5-30 MosA in the addition of a methyl group to the rhizopine 3-O-MSI}

The rhizopines 3-O-MSI and SI produced by strains L5-30 and $R \mathrm{~m} 220-3$, respectively, only differ by the presence of a methyl group on the former compound (Fig. 3). At the genetic level, the Rm220-3 mos locus differs from L5-30 by having an extended ORF1 and by the complete absence of $\operatorname{mos} A$. Since an ORF1 gene product is not required for rhizopine production in L5-30, it is most likely that MosA is a methylase involved in the conversion of SI to 3-O-MSI.

To test this we constructed an in-frame deletion of mos $A$ from the L5-30 mos locus and investigated its effect on rhizopine production in nodules. This involved the removal of an internal $771 \mathrm{bp} B a m \mathrm{HI}$ fragment from $\operatorname{mos} A$. After blunt-ending and re-ligation of the construct, sequencing showed that an additional $84 \mathrm{nt}$ were removed from around the $B a m \mathrm{HI}$ site by this procedure. The deletion is from 1535-2389 nt of the L5-30 mos sequence and results in an extensively truncated in-frame $\operatorname{mos} A$ consisting of $144 \mathrm{bp}$ (see Fig. 5). To investigate the effect of this mutation on the synthesis of the rhizopine, this $R$. meliloti L5-30 mos $A$ mutant and control strains producing 3-O-MSI and SI were separately inoculated onto alfalfa plants. Nodules were analysed for rhizopines. The results of HVPE analysis for rhizopine production in nodule extracts are shown in Fig. 6. The L5-30 mos $A$ control construct pJPM5 (the starting clone for the $\operatorname{mos} A$ deletion) in R. meliloti $\mathrm{Rm} 1021$ produces 3-O-MSI (Fig. 6; lane 2) whereas the L5-30 mos $A$ deletion construct pJPM6 in $\mathrm{Rm} 1021$ synthesizes SI (Fig. 6, lane 3) in nodules.

The MosA mutant strain produces SI rather than 3-OMSI and, as mentioned above, there is no other copy of 




Fig. 6. HVPE detection of rhizopines from nodule extracts. Lane 1, markers (A, 2-deoxy-adenosine; B, mannitol); lane 2. Rm1021(pJPM5) (L5-30 mosA control construct); lane 3, Rm1021(pJPM6) (L5-30 mosA deletion mutant); lane 4, Rm220-3 (SI control); lane 5, L5-30 (3-O-MSI control); and lane 6, Rm1021 (negative control). Each sample represents the rhizopine extract from $12.5 \mathrm{mg}$ (wet wt) of nodules.

$\operatorname{mos} A$ in the genome, therefore it is likely that $\operatorname{mos} A$ codes for a methylase involved in the addition of a methyl group to $S I$ in the synthesis of 3-O-MSI in symbiotic nodules. This is despite the extensive amino acid similarity between MosA and DapA, a dihydrodipicolinate synthase, from E. coli (Richaud et al., 1986; Murphy et al., 1993). The possibility that MosA affects methylation indirectly rather than by acting as a methylase per se has not been eliminated.

Since no ORF1 translation product can be found, MosB and $\mathrm{Mos} C$ must be involved in the production of $S I$. Sequence homology suggests MosB is a regulatory protein (Murphy et al., 1993), and the hydrophobicity profile, as well as immunogold studies (W.G. \& P. J . M., unpublished results) implicate $\operatorname{Mos} C$ as a transport protein in this process. Such a gene structure takes advantage of pre-existing pathways in bacteria to produce the rhizopine. A recent analysis of the L5-30 moc catabolism genes from L5-30 also indicates that this locus utilizes other pathways already present in bacteria (Rossbach et al., 1994).

\section{Level of rhizopine expression}

Strains containing the mos $A$ deletion plasmid (pJPM6) did not produce as much rhizopine $(S I)$ as did strains containing the parent plasmid (pJPM5, which produces 3$O$-MSI), (Fig. 6, lanes 2 and 3 ). These plasmids differ only by the $\operatorname{mos} A$ gene being truncated to a small, nonfunctional 144 bp ORF.

As all rhizopine strains tested catabolize both $\mathrm{SI}$ and 3-OMSI equally well (M. Wexler, personal communication) it is unlikely that the differing amounts of rhizopine is due to preferential catabolism of SI compared with 3-O-MSI. The differential expression of rhizopine may therefore be due to the reduction in translation of MosB and MosC as a result of the small non-functional upstream reading frame (present in pJPM6) as has been reported in polycistronic mRNA in eukaryotes (Fütterer \& Hohn, 1992). Alternatively, since $S I$ is a likely precursor in the biosynthetic pathway of 3-O-MSI the absence of a functional $\operatorname{mos} A$ gene, and the resulting accumulation of $S I$, may result in end-product inhibition by $S I$.

\section{Evolution of rhizopine genes}

This study indicates that either the $\mathrm{Rm} 220-3$ mos locus has arisen as a result of $\operatorname{mos} A$ and the surrounding sequence being deleted from the L5-30 mos locus (or a closely related strain), or the L5-30 mos locus arose from an insertion within the $\mathrm{Rm} 220-3$ mos locus. As deletions in symbiotic plasmids are common (Romero et al., 1991), we consider it most likely that the Rm220-3 mos locus is the result of a deletion. Consistent with this suggestion a recent survey of the frequency of inositol rhizopines has shown that only one strain ( $\mathrm{Rm} 220-30)$ out of 22 rhizopine strains isolated produced SI (Wexler et al., 1995). Furthermore, $\mathrm{Rm} 220-3$ can catabolize 3-O-MSI as well as $S I$ and restriction-fragment-length polymorphism of Rm220-3 and L5-30 catabolic genes shows them to be very similar (1.5\% divergence, Saint et al., 1993). Together these data suggest $\mathrm{Rm} 220-3$ is derived from a deletion of a 3-O-MSI producing strain.

With the exception of the $\operatorname{mos} A$ deletion, the mos genes from these two rhizopine strains show a high degree of conservation. Similarly, restriction-fragment-length polymorphism indicates that other rhizopine mos genes are also similar $(4.5 \%$ divergence in R. meliloti and $1.6 \%$ in $R$. leguminosarum bv, viciae, M. Wexler, personal communication). These rhizopine strains were isolated from geographically widespread regions. This may reflect the spread of rhizopine strains with the dissemination of cultivated pasture plants, followed by the rapid adaptation of the bacteria to the new environment.

Despite extensive DNA sequence conservation and geographical dispersal of rhizopire strains, only $10 \%$ of $R$. meliloti and $R$. leguminosarum bv. viciae strains are rhizopine strains. That the percentage is not higher might reflect a recent evolution and on-going dispersal of rhizopine genes in natural populations. The plasmid localization of rhizopine genes in all rhizopine strains studied to date $(\mathrm{M}$. Wexler, personal communication) would aid in this 
process. Further explanations could be that rhizopine genes only function in strains with a particular chromosomal background, or the presence of different rhizopines in other strains. In this sense it should be noted that if all strains had the same rhizopine there would be no advantage for a particular strain in intra-species nodule competition.

\section{ACKNOWLEDGEMENTS}

We thank N. Featherstone for technical assistance and $M$. Wexler for helpful discussion. This work was supported by the Australian Research Council. W.G. was supported by an RIRDC fellowship.

\section{REFERENCES}

Alexander, D. (1987). An efficient vector-primer cDNA cloning system. Methods Enzymol 154, 41-64.

Beringer, J. E. (1974). R factor transfer in Rbizobium leguminosarum. $J$ Gen Microbiol 84, 188-198.

Devereux, J., Haeberli, P. \& Smithies, O. (1984). A comprehensive set of sequence analysis programs for the VAX. Nucleic Acids Res 12, 387-395.

Döring, H.-P. \& Starlinger, P. (1986). Molecular genetics of transposable elements in plants. Annu Rev Genet 20, 175-200.

Figurski, D. H. \& Helinski, D. R. (1979). Replication of an origincontaining derivative of plasmid RK2 dependent on a plasmid function in trans. Proc Natl Acad Sci US A 76, 1648-1652.

Friedman, A. M., Long, S. R., Brown, S. E., Buikema, W. J. \& Ausubel, F. M. (1982). Construction of a broad host range cosmid cloning vector and its use in the genetic analysis of Rhizobium mutants. Gene 18, 289-296.

Futterer, J. \& Hohn, T. (1992). Role of an upstream open reading frame in the translation of polycistronic mRNAs in plant cells. Nucleic Acids Res 20, 3851-3857.

Henikoff, S. (1984). Unidirectional digestion with exonuclease III creates targeted breakpoints for DNA sequencing. Gene 28, 351-359.

Knauf, V. C. \& Nester, E.W. (1982). Wide host range cloning vectors: a cosmid clone bank of an Agrobacterium Ti plasmid. Plasmid 8, 45-54.

Kondorosi, A., Kiss, G. B., Forrai, T., Vincze, E. \& Banfalvi, 2. (1977). Circular linkage map of Rbizobium meliloti chromosome. Nature 268, 525-527.

Kowalski, M. (1967). Transduction in Rhizobium meliloti. Acta Microbiol Pol 16, 7-12.

Meade, H. M., Long, S. R., Ruvkin, G. B., Brown, S. E. \& Ausubel, F. M. (1982). Physical and genetic characterization of symbiotic and auxotrophic mutants of Rbizobium meliloti induced by transposon Tn5 mutagenesis. J Bacteriol 149, 114-122.

Miller, J. H. (1972). Experiments in Molecular Genetics. Cold Spring Harbor, NY: Cold Spring Harbor Laboratory.
Murphy, P. J. \& Saint, C. P. (1992). Rhizopines in the legume-Rhizobium symbiosis. In Molecular Signals in Plant-Microbe Communication, pp. 377-390. Edited by D. P. S. Verma. Boca Raton, FL: CRC Press.

Murphy, P. J., Heycke, N., Banfalvi, Z., Tate, M. E., de Bruijn, F., Kondorosi, A., Tempé, J. \& Schell, J. (1987). Genes for the catabolism and synthesis of an opine-like compound in Rhizobium meliloti are closely linked and on the sym plasmid. Proc Natl Acad Sci US A 84, 493-497.

Murphy, P. J., Heycke, N., Trenz, S. P., Ratet, P., de Bruijn, F. J. \& Schell, J. (1988). Synthesis of an opine-like compound - a rhizopine - in alfalfa nodules is symbiotically regulated. Proc Natl Acad Sci US A 85, 9133-9137.

Murphy, P. J., Trenz, S. P., Grzemski, W., de Bruijn, F. J. \& Schell, J. (1993). The Rbizobium meliloti rhizopine mos locus is a mosaic structure facilitating its symbiotic regulation. $J$ Bacteriol 175, 5193-5204.

Murphy, P. J., Wexler, M., Grzemski, W., Rao, J. P. \& Gordon, D. (1995). Rhizopines - their role in symbiosis and competition. Soil Biol Biocbem (in press).

Richaud, F., Richaud, C., Ratet, P. \& Patte, J.-C. (1986). Chromosomal location and nucleotide sequence of the Escherichia coli dap $A$ gene. J Bacteriol 166, 297-300.

Romero, D., Brom, S., Martínez-Salazar, J., de Lourdes Girard, M., Palacios, R. \& Dávila, G. (1991). Amplification and deletion of a nod-nif region in the symbiotic plasmid of Rbizobium phaseoli. $J$ Bacteriol 173, 2435-2441.

Rossbach, S., Kulpa, D. A., Rossbach, U. \& de Bruijn, F. J. (1994). Molecular and genetic characterization of the rhizopine catabolism (mocABRC) genes of Rbizobium meliloti L5-30. Mol \& Gen Genet $245,11-24$.

Saint, C. P., Wexler, M., Murphy, P. J., Tempé, J., Tate, M. E. \& Murphy, P. J. (1993). Characterization of genes for synthesis and catabolism of a new rhizopine induced in nodules by Rhizobium meliloti $\operatorname{Rm} 220-3$ : extension of the rhizopine concept. $J$ Bacteriol 175, 5205-5215.

Sambrook, J., Fritsch, E. F. \& Maniatis, T. (1989). Molecular Cloning: a Laboratory Manual, 2nd edn. Cold Spring Harbor, NY: Cold Spring Harbor Laboratory.

Sanger, F., Nicklen, S. \& Coulson, R. (1977). DNA sequencing with chain-terminating inhibitors. Proc Natl Acad Sci USA 74, 5463-5467.

Soto, M. J., Zorzano, A., Mercado-Blanco, J., Lepek, V., Olivares, J. \& Toro, N. (1993). Nucleotide sequence and characterization of Rhizobium meliloti nodulation competitiveness genes $n f e$.J Mol Biol 229, 570-576.

Wexler, M., Gordon, D. \& Murphy, P. J. (1995). The distribution of inositol rhizopine genes in Rhizobium populations. Soil Biol Biochem (in press).

Zasloff, M., Ginder, G. D. \& Felsenfeld, G. (1978). A new method for the purification and identification of covalently closed circular DNA molecules. Nucleic Acids Res 5, 1139-1152.

Received 4 August 1994; revised 27 February 1995; accepted 7 March 1995. 